\title{
Harry Collins and Robert Evans (2017) Why Democracies Need Science. Polity Press: Cambridge. 200 pages. ISBN: 978-1-5095-0960-7
}

\author{
Vira Bushanska \\ vira.bushanska@rub.de
}

Postmodernist critique is often represented as incapable of producing meaningful alternatives to the phenomena criticized, which in turn leads to claims that overcoming postmodernism is necessary. Harry Collins and Robert Evans make a similar move in Why Democracies Need Science. They see government as informed by scientific values under the threat of erosion by the freemarket ideology that leads to assessing science in terms of utility and economic value, as well as by the mass media, as distorting science for reasons of profit. Postmodernist critique claiming that there is no truth to be found, but rather that there are many approaches intertwining with politics, undermines scientists who attempt to assert themselves and their values.

In response Collins and Evans propose elective modernism as a kind of post-post-modernism in science and technology studies, a move that resists the devaluation of science by representing the latter as a case of moral choice. Elective modernism endorses the enriched critical understanding of science provided by the STS since 1970s, but draw implications allowing or even urging us to opt for science. While philosophical and utilitarian defenses of science often fail, this moral approach allows scientific expertise to be valued even in times of epistemological and practical weakness.

Collins and Evans draw on values, the formative aspirations of science as a form of life, such as observation, corroboration, falsification, and the
Mertonian social norms of communism, universalism, disinterestedness, organized skepticism, and so on, even though these are aspirations and might never be achieved in scientific practice. These values are said to be "just good in a selfevident kind of way" (p. 48) when it comes to knowing the observable world. It is these values that make scientists do 'good' science - through being aspired to, not necessarily accomplished and that make us prefer experts to non-experts, even though the latter may be no less wrong in their conclusions. Collins and Evans draw on common sense to demonstrate that holding those aspirations is self-evidently preferable. For example, one would self-evidently prefer a judgment of a person who has observed an object over the judgment of one who has not, and so on.

This choice is said to be a moral one as the authors see the formative aspirations of science as inherently connected to the way the Western societies and, more generally, democracies exist. Due to its formative aspirations, science "supports democracy through its very existence" and "gives substance to the way of being of democracy" ( $p$. 145). Democracies thus need science not because of objective truth or economic utility, but because "it is, or can be, a fountainhead of good values" ( $p$. 19), providing moral leadership to the society.

Collins and Evans further argue that it is important to keep science and politics separate (as a formative aspiration) to minimize political bias. They distinguish between a technical phase 
of decision-making, involving scientists and other experts, and a political phase, where the findings of the technical phase are to be considered, adopted or overruled. In order to provide this separation, they propose a new institution. The particular expertise of 'The Owls' informs democratic policy-making through identifying the current state of scientific consensus on a certain issue. Of course scientific discourse is open-ended and every finding might be revisited in the future, but consensus is a social fact, and not a natural fact, so it is a well-honed understanding of social processes of science that is the expertise of the Owls. The institution should consist of natural scientists who understand STS, and social scientists who adhere to both the postmodernist critique of science and elective modernism. These scientists, capable of understanding both the perspective of practical science and of the STS, are similar to owls, capable of turning their heads to $180^{\circ}$ and looking in the opposite direction.

The authors stress that elective modernism (the 'Third Wave of STS') adheres to the Second Wave critique and the disagreement is only about implications. Elective modernism defends scientific values even at times of epistemological and practical weakness representing science as a case of moral choice. At the same time, it allows one to proclaim the cultural status of science without being accused of unreflective scientism - by adhering to the Second Wave critique and rendering scientific values as formative aspirations.

However the difference in implications between the two approaches-what the authors name as the Second and Third Waves of STS, seems to be more significant than the authors acknowledge. They basically seem to reject the Second Wave claim that it is necessary to "reorder power relationships: to make the exercise of power more reflexive, responsible, inclusive, and more equal [through new approaches to science and technology]" (p.104), by instead stressing the need to keep science and politics separate. They argue that to "preserve science as a distinctive form of life, scientists have to ignore, in a determined way, what the reflective analysts of science say [...] Natural scientists [...] have responsibility only to their world" (p. 76).
Collins and Evans argue for the preservation of science's traditional values that are seen as "eternal" (p. 19). For the authors this means a moral choice connected with the preservation of the way the Western societies exist. An opposite choice is equated with "the dissolution of our society. A society in which the weight of an opinion is not increased according to the expertise of the opinion holder [...] is a society that would have quite different institutions and procedures from those of the developed and developing world" ( $p$. 58).

The authors base the defense of their arguments on the common sense of science as a good. However they refer to science as a process of co-production-a process in which the practices of knowledge-making "produce both the objects that make up our world and the social institutions and norms that give those objects their meaning" (p. 106 f) and in which common sense might be seen as co-produced by science as well. It is then problematic to claim that 'selfevident' arguments are irrefutable as the practices of knowledge-making are often "drawing on and reproducing pre-existing hierarchies of power and status" (p. $106 \mathrm{f}$ ). The authors do not recognize this contradiction and praise the choice of science as the only morally correct one. Yet the possibility to criticize such a choice is bounded already in the introduction:"the alternatives [to the moral choice of science] cannot be proved to be abhorrent but if they do not seem immediately abhorrent to you then there is something wrong with you - in the same way as there was something wrong with the person who was going to torture children gratuitously" (p. 21).

The book makes an important claim that valuing science is a moral choice - a claim I have never met in such an explicit form before, the implications of which are worth investigating. Also the interrelation between valuing science and the ways the Western societies exist is an important issue to raise. However, the book is written in a very programmatic and ultimate way bounding the possibility of critique, expressing a particular political agenda which does not necessarily correspond to the authors' stressing the need of keeping politics and science separate and opting for 'science debate' instead of 'science war' (p. 151). 